\title{
Other echoes in the garden
}

\author{
JAMELIE HASSAN
}

I want to begin with a 'narrative memory' - a term I borrow from Neil McLeod's recent book Cree Narrative Memory - to introduce my billboard project Linkage. McLeod, speaking inreference to storytelling and indigenous peoples, notes that 'it is a sense of place that anchors our stories; it is the sense of place that connects us together as communities. Indeed, it is the sense of space that connects us to other beings and the rest of creation'. ${ }^{1}$

Thirty years ago, I had an opportunity to travel to Iraq. I was on an international scholarship for students of Arabic language at the University of Mustansyria in Baghdad. In March 1979, I travelled to the marshlands of southern Iraq where the Tigris and Euphrates Rivers meet. I had learned about this fragile ecological site while in Canada, where I had completed artwork on projects related to water plants and their environments. I made the trip to the marshes to learn more and document the area. I found that women were often the ones who gathered the reeds, making bundles that were used to construct the traditional guesthouses, called muthifs. Significantly, among the Cree, the bundle is also considered a metaphor for memory and storytelling. ${ }^{2}$ The muthif was offered as a magnificent place of respite for travellers and guests. During the day, accompanied by a small group, I followed along the narrow pathways that led us by land and water through the marshes, our boat moving slowly through corridors of green reeds that dominated and shaped the landscape, passing isolated and temporary islands, with makeshift structures built from bundles of the same reeds. My host, the Iraqi matriarch of the marshland community, facilitated my movements. I wanted to document with my camera and in watercolour paintings. It was the slow act of doing watercolours that I believe gave me greater access. My slow and transparent act of painting - a constant - created an openness between myself and the community. Often I was directed by my host, a diminutive agile elder, wearing a black abiya, as to what she thought I should paint; I considered myself an answerable participant, and was in a state of considerable energy, continuously wanting to paint. I created a number of paintings, specifically as gifts, which remained with them as traces of my visit.

1 McLeod, Neil 2007, Cree Narrative Memory, from Treaties to Contemporary Times, Purich Publishing Ltd, Saskatoon, Saskatchewan.

2 Ibid. 
Linkage was originally produced as part of a billboard project organised by the Mendel Art Gallery in Saskatoon, Canada, as part of the Post-Colonial Landscape in July 1993. Linkage presents reminders of the disastrous environmental effects to Iraq's gulf region of 1991's 'Operation Desert Storm'. Coalition forces used radioactive bullets and shells recycled from nuclear waste. In an article published in the London Free Press in March 1993, Canadian Dr Eric Hoskins estimated that coalition forces fired 40 tonnes of nuclear waste into Iraq during the Gulf War:

In Iraq, the health authorities say that at least three times more children are being born with congenital deformities than before the Gulf War... During the 100-hour ground war of February 1991, coalition planes fired at least 1 million rounds of ammunition coated in radioactive material known as depleted uranium, or DU...According to the US Department of Defence, at least 40 tons of DU were left on the battlefields of southern Iraq. ${ }^{3}$

During the billboard's first presentation in Saskatoon, community activists in the anti-nuclear movement came forward to support the artwork. As curator, Joyce Whitebear Reed, noted in her writing on this work:

A current article published in the Saskatchewan-based publication Briarpatch [May 1993] further suggests an unexpected link between the Saskatchewan uranium industry and the use of nuclear waste in the Gulf War. We are reminded that the post-colonial landscape is also a multi-national, post-industrial landscape. ${ }^{4}$

It is now believed that the figure is closer to 400 tonnes. Initially under reported, the serious environmental contamination of soil and water in Iraq became a news story when links were made to the Gulf War Syndrome, a debilitating condition that some of the coalition soldiers experienced. International medical personnel suspected that depleted uranium (DU) could have caused a mysterious increase in cases of leukemia among Iraqi children and a high rate of infant mortality and birth deformities.

Japan has dedicated \$11 million towards the restoration of the marshlands of Iraq, which Saddam Hussein also targeted in an act of 'ecocide' when he ordered the draining of the marshes after the first Gulf War. This fabled wetland and probable site of the Garden of Eden had been a place of refuge and a base for rebel Shia forces fighting against Saddam. Further devastation of more that 90 per cent of the marshland has 'changed the weather and turned a vast area into desert, releasing pollution into the Gulf':

\footnotetext{
3 Maggie O'Kane in the Guardian Weekly, 10 January 1999. See War Zones, Presentation House Gallery, Vancouver, catalogue edition of Collapse \#6, 2000, Jamelie Hassan, artist, pp.88-9.

4 Joyce Whitebear Reed, curator for the billboard project of the Post-ColonialLandscape catalogue published by Edmonton Art Gallery/Mendel Art Gallery, Saskatoon,Canada, 1997, pp. 8-9.

5 Paul Brown in the Manchester Guardian Weekly, 30 July - 5 August 2004.
} 
The ancient Iraqi marshland drained by Saddam Hussein as punishment against their occupants are back [to] almost $40 \%$ of their former level. According to the United Nations Environment Programme (UNEP)... the latest satellite imagery showed a 'phenomenal' recovery rate for the southern marshlands, back to almost 3,500 sq. km after dwindling to just 760 sq. $\mathrm{km}$ in 2002. Saddam began moving against the Marsh Arabs in the early 1990s accusing them of supporting a Shia Muslim uprising after the first Gulf War. A combination of dams and canals blocked water from the marshes, turning a pristine, wetland ecosystem into a semi-desert and forcing all but 40,000 of the area's 450,000 inhabitants to flee. But after Saddam was toppled in 2003 residents began returning and breaking the barriers, letting water flow freely in a region where people had lived on small islands and moved wooden boats for thousands of years. ${ }^{6}$

I return to the Cree of the prairies where this billboard was first presented and acknowledge the linkages between communities, their survival and links to the land. Writing of a visit from a Cree elder, Neil McLeod recalls being told that the 'land does not echo...that the land no longer had sound the same way it had before' $^{7}$

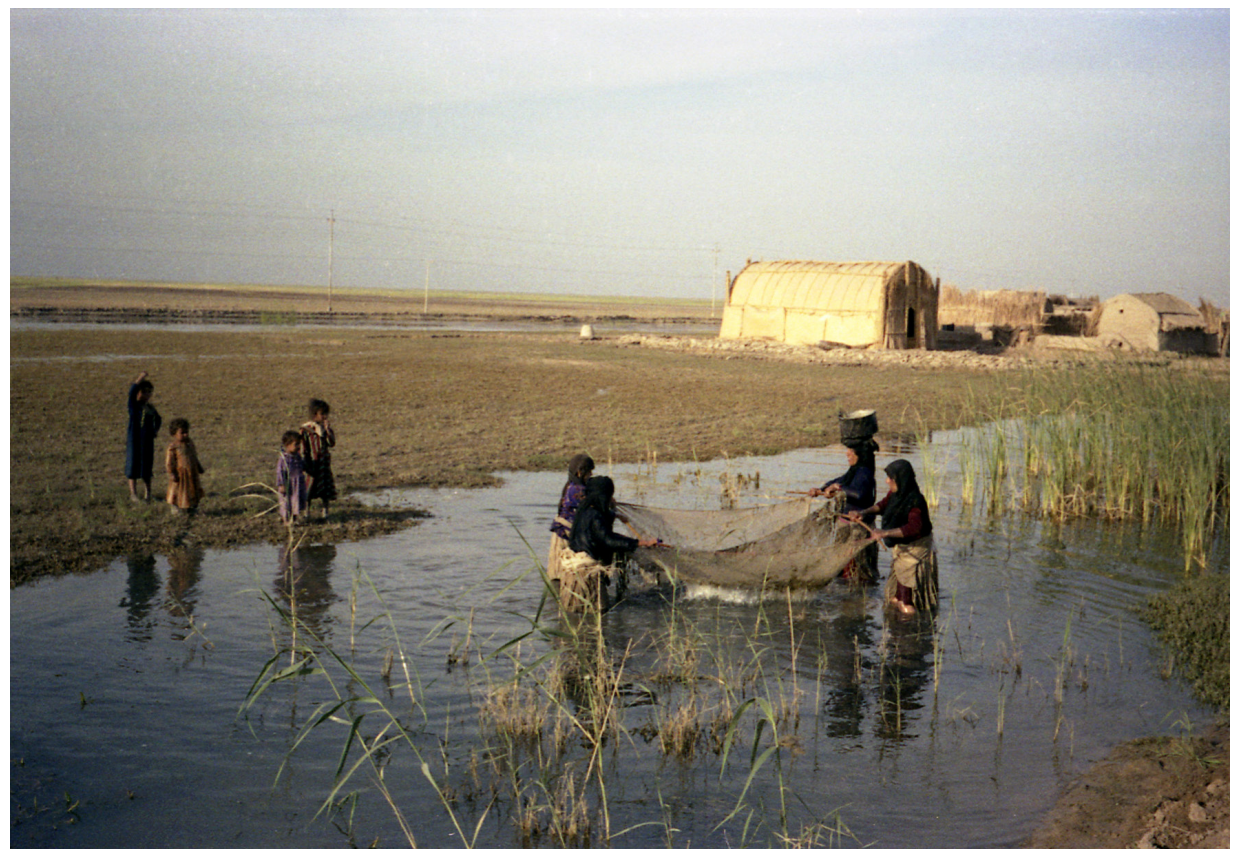

Figure. 1, Woman fishing, marsh land, southern Iraq, 1979. Photo credit: Jamelie Hassan

6 'Field Notes', Guardian Weekly, 2-8 September 2005.

7 McLeod, Cree Narrative Memory. 


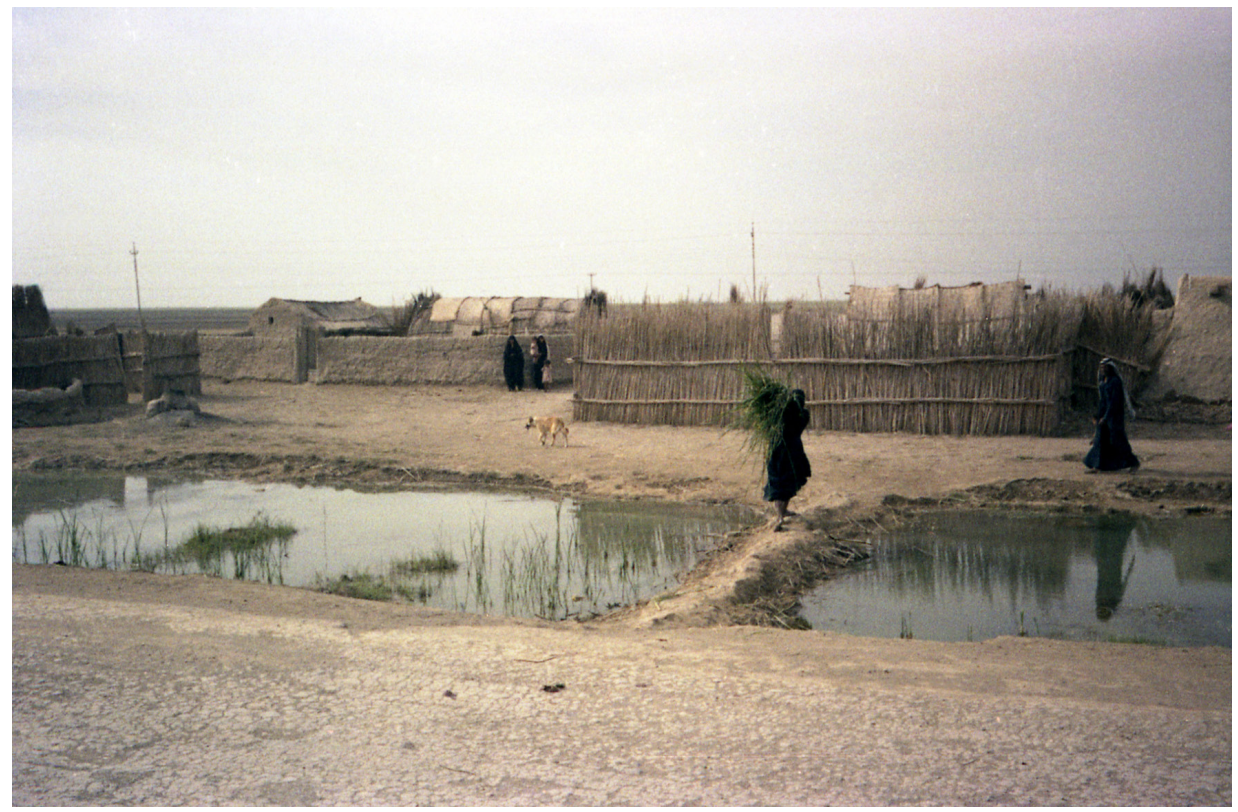

Figure. 2, Woman carrying reeds for bundles, marsh land, southern Iraq, 1979. Photo credit: Jamelie Hassan

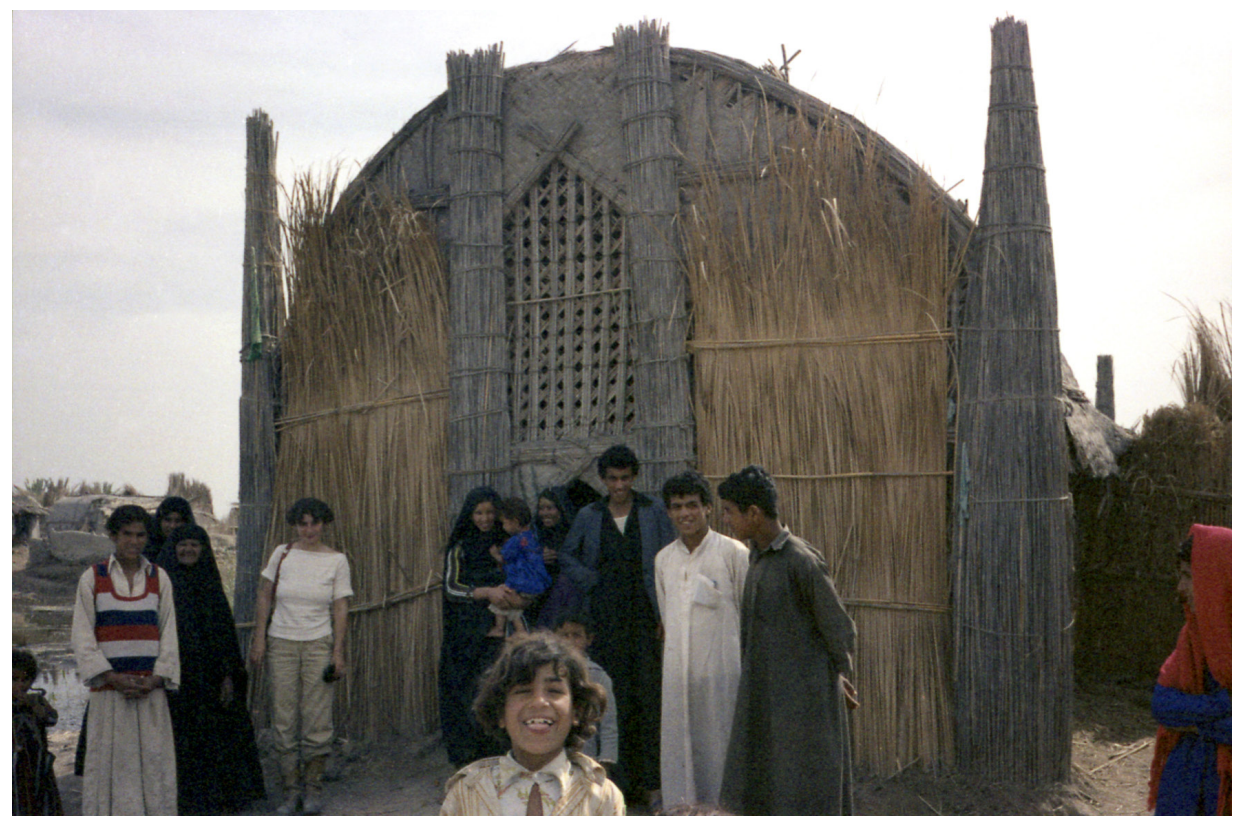

Figure. 3, Group photo with muthif in background; artist in white top standing on left of doorway with elder matriarch to her left. Marsh land, southern Iraq, 1979. Photo courtesy of Jamelie Hassan 


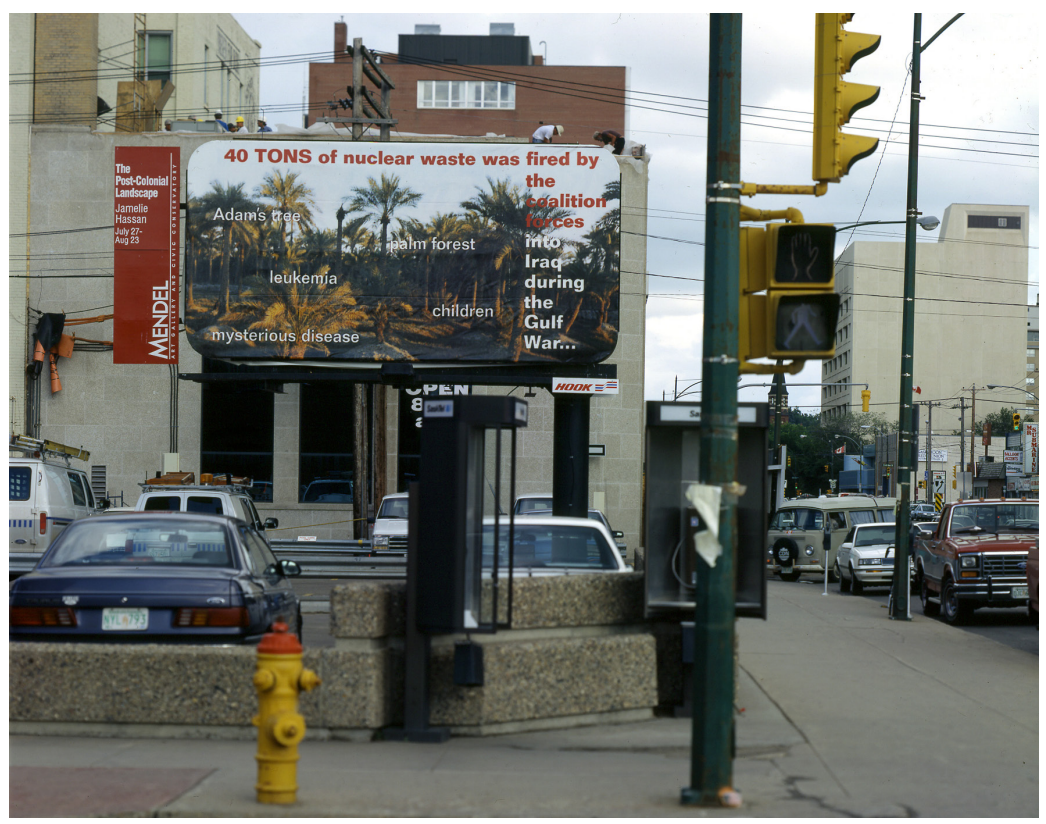

Linkage, billboard by Jamelie Hassan, Saskatoon, Canada for Post-Colonial Landscape exhibition, 1993. Photo courtesy of Mendel Art Gallery, Saskatoon, Canada

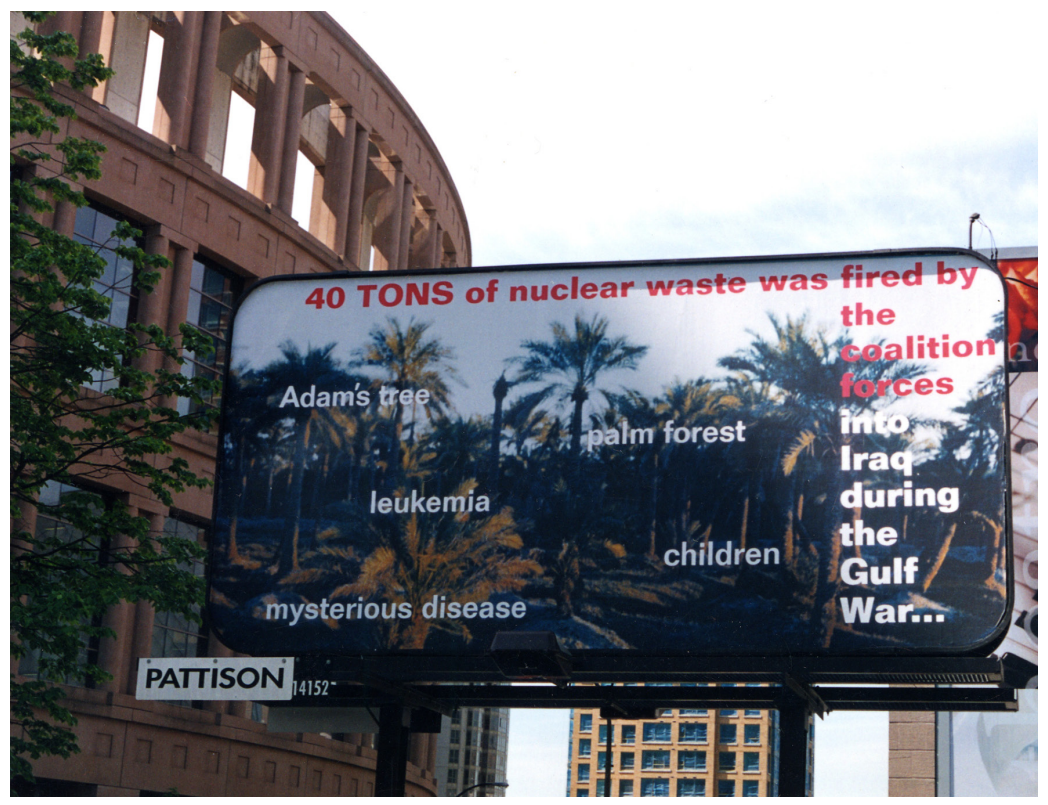

Linkage, billboard by Jamelie Hassan, Vancouver Public Library, Vancouver, Canada for War Zones exhibition, 1999. Photo credit: Robert Keziere. 


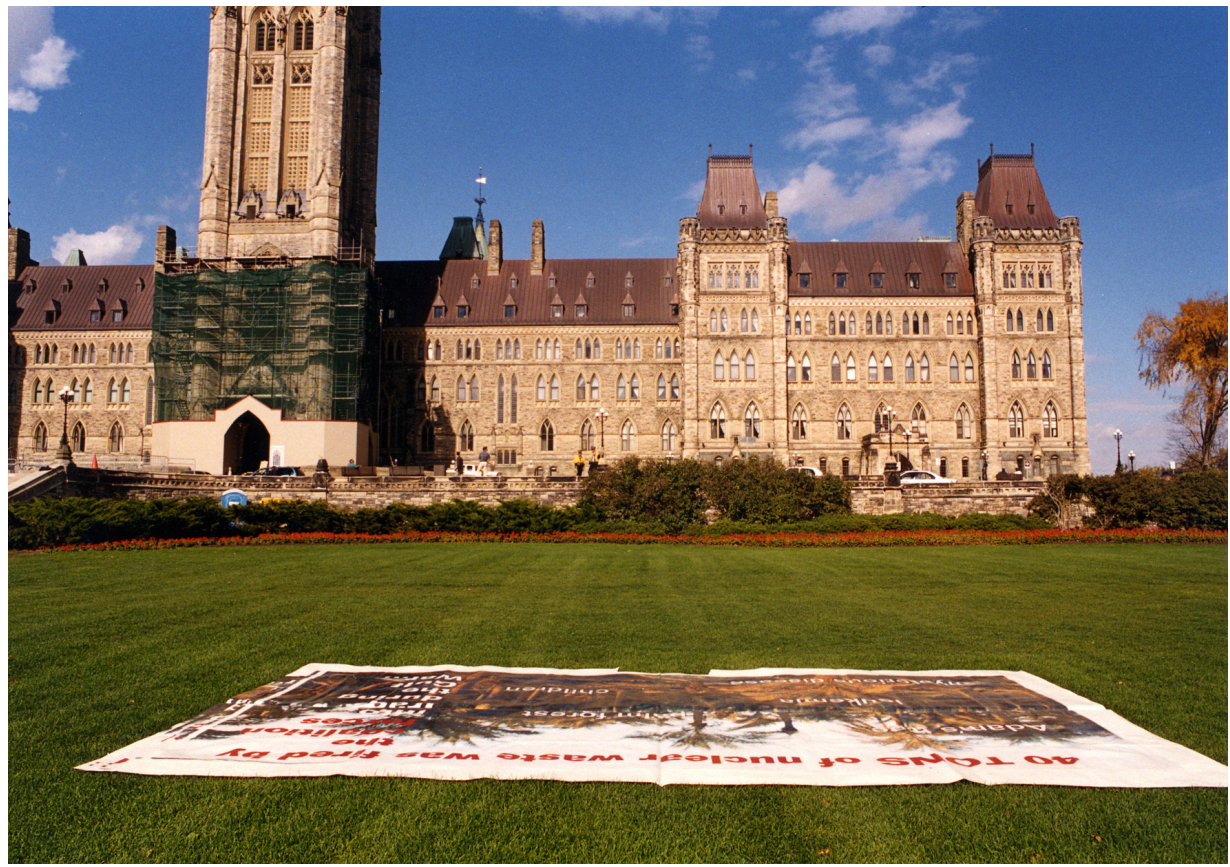

Linkage, billboard by Jamelie Hassan, laid out on grounds of Parliment Building, Ottawa by anti-war protestors 2001. Photo credit: Rawi Hage.

400 TONELADAS de desechos nucleares fueron disparados

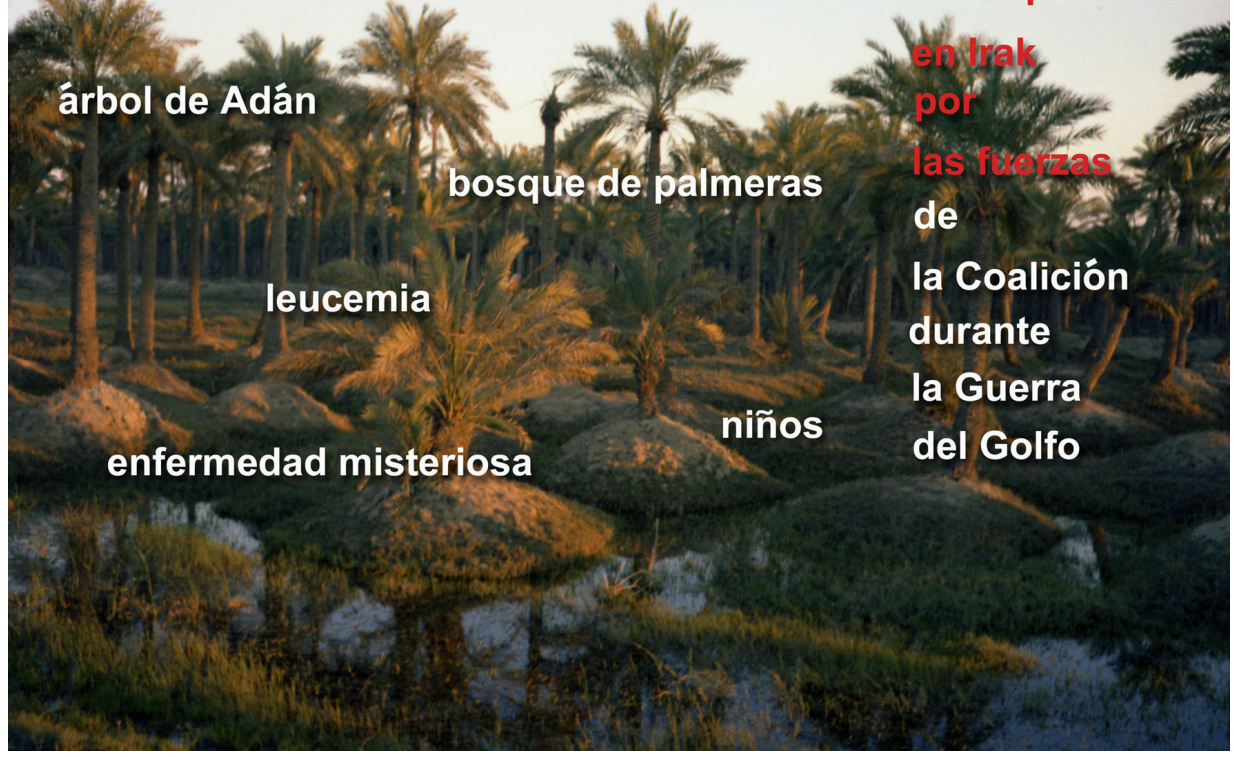

Linkage, billboard by Jamelie Hassan, updated Spanish version presented at 10th Havana Biennial of Havana, 2009. Photo courtesy of Jamelie Hassan. 